\title{
O CONCEITO DE TRABALHO ALIENADO EM KARL MARX NA SOCIEDADE CAPITALISTA: Discussões filosóficas na modernidade nos manuscritos econômicos
}

\author{
The concept of work alienado in Karl Marx in the capitalist society philosophical \\ discussions in modernity in the economic manuscripts
}

\section{Edmilson Gomes da Silva ${ }^{1}$}

\begin{abstract}
RESUMO: O objetivo desta pesquisa é analisar o conceito de trabalho alienado no pensamento de Karl Marx na sociedade moderna capitalista aos conhecimentos filosóficos nos manuscritos econômicos - filosóficos,1844. Desse modo, o trabalho alienado é fundamental para um debate e discussões filosóficas na teoria marxista e o liberalismo econômico na modernidade. Na discussão teórica - filosófica, Marx discute o conceito de trabalho alienado a partir de uma crítica aos fundamentos econômicos e políticos na sociedade do mercado/capitalista. Contudo, a literatura teórica é apresentada nos manuscritos econômicos - filosóficos. Nesta obra, Marx faz crítica aos filósofos fisiocratas de Adam Smith e David Ricardo. Estes consideram o trabalho como de fonte de riqueza do trabalhador. Assim, trabalho e alienação vão na lógica sob o processo da mais valia dos sujeitos como a exploração da força do trabalhador para manter a relação econômica para o sistema de produção capitalista. Dessa forma, A metodologia utilizada foi uma pesquisa bibliográfica no pensamento marxista sobre e o conceito de trabalho alienado na sociedade capitalista.
\end{abstract}

Palavras-chave: Trabalho alienado. Sociedade moderna capitalista. Pensamento Marxista.

ABSTRACT: The objective of this research is to analyze the concept of work alienated in the thought of Karl Marx in modern capitalist society to the philosophical knowledge in the economic - philosophical manuscripts, 1844. Thus alienated labor is central to a debate and philosophical discussions in Marxist theory and economic liberalism in modernity. In the theoretical - philosophical discussion, Marx discusses the concept of alienated labor from a critique of economic and political foundations in the market / capitalist society. However, the theoretical literature is presented in the economic - philosophical manuscripts. In this work, Marx criticizes the physiocratic philosophers of Adam Smith and David Ricardo. These consider work as a source of

\footnotetext{
${ }^{1}$ Graduado em Licenciatura em Geografia. Especialista no ensino em Geografia pela Universidade de Pernambuco-UPE, Petrolina. Licenciando em Filosofia pela UFPI - Universidade Federal do Piauí. Pós-Graduando em Ensino de Sociologia do Ensino Médio pela UFBA - Universidade Federal da Bahia. Aluno Especial do Mestrado do Programa de Pós-graduação stricto sensu Formação de Professores e Práticas Interdisciplinares (PPGFPPI).
} 
worker wealth. Thus, work and alienation go in logic under the process of the surplus value of the subjects as the exploitation of the worker's strength to maintain the economic relation to the capitalist production system. Thus, the methodology used was a bibliographical research in Marxist thinking about and the concept of alienated labor in capitalist society.

Keywords: Alienated labor. Modern capitalist society. Marxist thought.

\section{INTRODUÇÃO}

Este artigo apresenta uma discussão filosófica sobre o conceito de trabalho em Karl Marx na sociedade capitalista na modernidade nos Manuscritos Econômicos - Filosóficos. Neste sentido, o conceito de trabalho alienado é uma possibilidade sob a lógica do capital enquanto os sujeitos/trabalhadores vão vender sua força de trabalho para os capitalistas na sociedade industrial capitalista.

A obra dos Manuscritos Econômicos-Filosóficos discute a economia política e destaca Karl Marx como um dos principais filósofos da modernidade na essência da totalidade da crítica a economia política. Assim, o pensamento marxista vai dialogar sobre o conceito de trabalho e alienação dos indivíduos no modo de produção capitalista na lógica da mais valia. Na crítica filosófica, Marx vai no embate filosófico com os economistas David Ricardo e Adam Smith. Este considerado o pai da economia moderna vai ressaltar a importância do trabalho como uma atividade produtiva para o desenvolvimento econômico e a uma fonte de riqueza na nação.

Neste sentido, o objetivo deste artigo é investigar o conceito de trabalho alienado no pensamento marxiano na sociedade moderna capitalista à luz nos manuscritos econômicos - filosóficos.

Consequentemente, o trabalhador vende sua força de trabalho para trocar pelo salário no final do mês. Assim, o capitalista ganha o lucro pela força do trabalho dos trabalhadores como um grande comércio que se transforma em mercadoria e estranhamento dos sujeitos que produz para o modo de produção e o enriquecimento da classe burguesa. Assim, o trabalho humano é o grande motor de toda riqueza adquirido pela classe dominante e a alienação dos dominados para o meio de produção capitalista através do trabalho. 
Desse modo, as relações de trabalho e a alienação são consequência para um trabalhador alienado para fortalecer ganho do homem sobre o homem nos meios de capital e o modo de produção capitalista. Discute-se ainda o papel do reconhecimento dos sujeitos para uma luta de classe.

A metodologia foi desenvolvida a partir de um procedimento metodológico de uma pesquisa bibliográfica em estudo da obra clássica dos Manuscritos Econômicos - Filosóficos, a saber análise do trabalho alienado no pensamento marxista.

A primeira seção mostra á lógica capitalista na modernidade, que é discutido o trabalho alienado nos manuscritos econômicos - filosóficos, possibilitando os estudos marxistas na essência filosófica para os estudos da política e economia. A segunda seção mostra a pesquisa de Karl Marx sobre o conceito de trabalho alienado, que discorre o embate filosófico com os pensadores da modernidade.

Desta forma, neste estudo científico, deve-se em uma análise filosófica dos estudos de Marx para fundamentação teórica na economia política. Por fim, proporciona o conceito de trabalho alienado enquanto um processo produtivo no fortalecimento do modo de produção das fábricas da modernidade.

\section{A SOCIEDADE MODERNA CAPITALISTA: DISCUSSÕES FILOSÓFICAS NOS MANUSCRITOS ECONÔMICOS-FILOSÓFICOS}

A Revolução Industrial tem o contexto histórico - social no século XVIII na Inglaterra. Assim, as relações para a produção industrial têm o seu auge em meados do século XIX. As relações do conceito teórico para o "trabalho" tiveram mudanças na totalidade para o modo de produção na sociedade moderna capitalista. Neste sentido, os filósofos pesquisaram na literatura teórica para compreender a economia moderna. Karl Marx fico considerado como um dos principais pensadores da época por pesquisar "o conceito de trabalho alienado tornou-se referência teórica para se entender a sociedade capitalista".

$\mathrm{Na}$ reflexão da obra Manuscritos Econômico - Filosóficos, Marx fundamentase o trabalhador alienado na sociedade moderna capitalista. Assim, a divisão social do trabalho proporciona a análise para explicar a "alienação de trabalhador" no processo industrial para alimentar o modo de produção capitalista.

O recorte do texto desta obra de Marx, apresenta-se o trabalhador da modernidade na indústria para o ciclo do processo produtivo capitalista. O 
manuscrito econômico - filosófico produzido em meados de 1844 na 'efervescência da revolução industrial na Inglaterra". Assim, Karl Marx e Adam Smith vão debater o trabalho na contrariedade do pensamento filosófica na economia política. De acordo com Bottomore (2012, p.195).

\begin{abstract}
Escrevendo numa fase bastante inicial da Revolução Industrial, Adam Smith percebeu a importância crucial da produção industrial. A divisão do trabalho na produção industrial tornava possível um crescimento sem precedentes da produção e da produtividade. Se fosse possível vender essa maior produção em um mercado, certamente a divisão do trabalho mostrar-se-ia lucrativa, e os lucros poderiam ser reinvestidos em atividades ainda mais lucrativas. Ao situar o crescimento da riqueza na relação da divisão do trabalho com o crescimento dos mercados, Adam Smith libertou a teoria econômica de uma inclinação agrária que lhe havia sido transmitida pelos fisiocratas e do estreito bias comercial que lhe fora impingido pelos mercantilistas.
\end{abstract}

O pensamento Marxista crítica a economia política na discussão filosófica a partir dos conceitos teóricos que são base para a exploração e a alienação do trabalhador na linha de produção da fábrica: "propriedade privada, separação do trabalho, capital e terra, salários, lucro do capital, valor de troca.

Em meados do século XIX, porém, o capitalismo havia ingressado na
fase do que Marx chamou de "indústria moderna" ( $O$ Capital, I,
caps.XIII e XIV) caracterizada pela produção da mais-valia relativa,
acompanhada da centralização do capital e do desenvolvimento das
instituições de crédito para facilitar essa centralização. Começou
assim a época conhecida como capitalismo monopolista, em que a
produção, em escala cada vez maior (concentração) criou a
tendência à monopolização em escala nacional e internacional
(BOTTOMORE,2012, p.301).

A sociedade moderna capitalista proporcionou o conceito de trabalho para alienação no pensamento Maximiano. Este modelo econômico político moderno influenciou o trabalho alienado na manipulação dos sujeitos enquanto processo da venda de sua força de trabalho no estranhamento da mercadoria.

Entender o trabalhador como um processo de alienação no processo industrial, permite-nos entrever a totalidade que envolve: capital, trabalho e a força do trabalho que faz parte do contexto histórico apresentado nesta discussão teórica, operadas desde o século XVIII, como vimos: a ruptura nas relações dos homens com a natureza, a ruptura. Conforme Marx (1983, p.148): 
Com a valorização do mundo das coisas aumenta em proporção direta a desvalorização do mundo dos homens. O trabalho não produz só mercadorias; produz a si mesmo e ao trabalhador como uma mercadoria, e isto na proporção em que produz mercadorias em geral.

Marx faz uma reflexão filosófica no mundo do trabalho enquanto condição para valorizar as coisas e desvalorizar o homem na essência da subjetividade do indivíduo. Por meio do trabalho, o ser humano constrói sua subjetividade e se aliena para produzir as mercadorias. Assim, o homem passa a se confundir com a mercadoria e o estranhamento do trabalho no modo de produção capitalista. No filme, tempos modernos, o personagem "Charles Chaplin" na linha de montagem da indústria se aliena nas máquinas para aumentar a produção no processo da "mais valia".

Figura1: Cena do filme Tempos Modernos (1936) - o ator Charles Chaplin representa o trabalhador

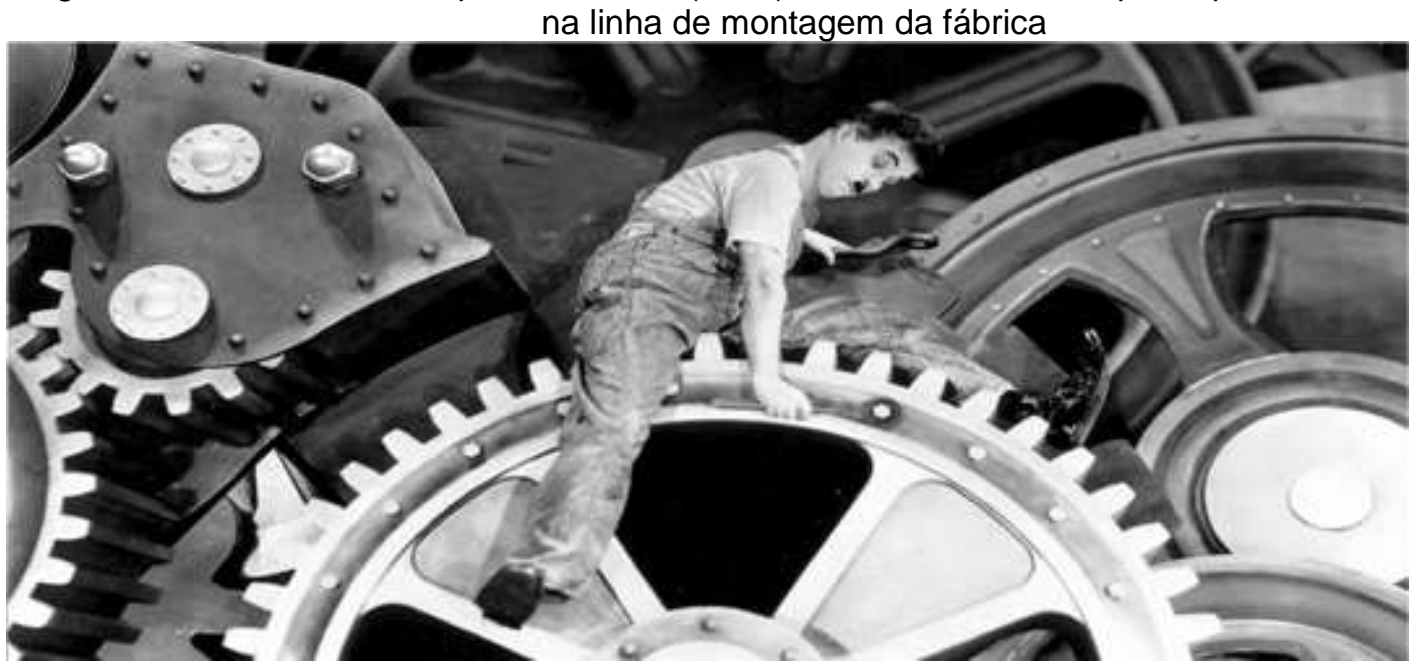

Fonte: ARANHA, Maria Lúcia de Arruda.2012.

No filme Tempos modernos, Marx crítica o modo de produção capitalista e como o trabalhador vai se alienar neste processo produtivo na crítica - um trabalho repetitivo que vai levar o indivíduo ao processo de alienação e um simples apertador de parafusos. Além disso, Marx crítica à sociedade burguesa na modernidade: alienação (perda do produto e de si mesmo), fetichismo (valorização da mercadoria em detrimento do trabalhador), reificação (transformação do ser humano em "coisa") e ideologia (ideias da classe dominante que ocultam a dominação por ela exercida). 
O período moderno possibilitou a relação do trabalhador e capital na essência da crítica de Marx na totalidade do modo de produção capitalista. Neste sentido, os trabalhadores precisariam trabalhar por linga jornada de trabalho para aumentar o lucro na produção.

Figura 2: Linha de montagem da Ford na década de 1920. Nesse modelo, cada trabalhador é especializado em uma etapa da produção e não tem o conhecimento para produzir o produto por

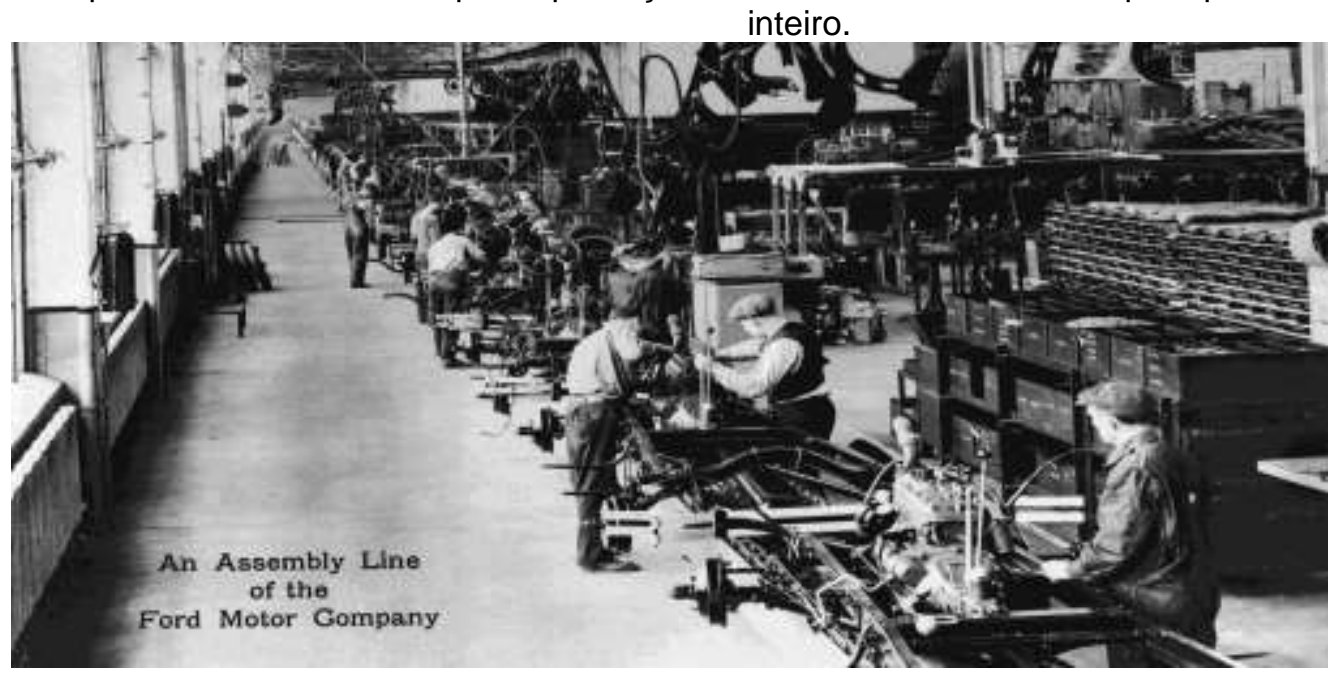

Fonte: ARANHA, Maria Lúcia de Arruda.2012.

\section{O CONCEITO DE TRABALHO ALIENADO EM KARL MARX}

O pensamento Marxista analisa o conceito de trabalho alienado quando 0 homem não se reconhece nas relações humanas do trabalho e entra no processo de alienação. Assim, a abstração do trabalhador fica estranhado com a vida social e o sujeito perde a consciência de si e passa a conviver alienado ao processo de ato produtivo das forças de trabalho. Na discussão teórica da divisão entre trabalho, capital e terra, a economia política é criticada por fazer parte do processo alienante dos sujeitos. Assim, conforme Marcuse (1968, p.108).

O objeto da crítica da economia política enquanto justificação cientifica, a saber, cobertura de uma "alienação" total e "desvalorização" da realidade humana, como a representa a sociedade capitalista - enquanto uma ciência que faz do homem o seu objeto, enquanto ser desnaturado..., cuja existência total é determinada através da „divisão entre trabalho, capital e terra, através de uma desumana divisão do trabalho, através de concorrência privada, etc. 
Karl Marx faz uma crítica a sociedade moderna capitalista na economia política para atribuir ao trabalho e a alienação na forma concreta das forças produtiva do trabalhador. Na literatura bibliográfica para conceituar o trabalho alienado, nos manuscritos econômico - filosófico, Karl Marx fundamenta teoricamente que o trabalhador é um alienado no processo industrial fabril taylorismo e fordismo na acumulação do capital. Em seu estudo, o filósofo húngaro István Mészáros aprofundando os estudos marxistas no livro a teoria da alienação (1970) escreve que o trabalhador é alienado e estranhado na sua atividade do ato produtivo.

O filósofo István Mészáros pesquisa nos manuscritos econômicos - filosóficos (1844) de Marx para fundamentar seu pensamento filosófico para compreender a ontologia do trabalho alienado/estranhado.

$\mathrm{Na}$ sociedade moderna capitalista, o pensamento marxista esclarece na economia política que a propriedade privada tem relação direta na totalidade no trabalho, alienação e o capital. Este é o mais importante que vai assegurar o ato produtivo (monopólio, valor, desvalorização e competição).

É mais o trabalho que o trabalhador que é o alienado, e é o trabalho alienado que afeta a maneira como o indivíduo se sente [...] a alienação é resultado da posse privada do capital e do emprego de trabalhadores por salário, um arranjo que concede a estes, pouco controle sobre o que fazem. (ALVES,2012 apud JOHNSON, 1997. p.06)

O sujeito enquanto ser genérico é livre em sua natureza para a transformação social e humana. No entanto, a liberdade é ameaçada quando o homem não se realiza na atividade do trabalho. Assim, o homem vai se alienar no ato da atividade produtiva do trabalho.

$\mathrm{Na}$ alienação do objeto do trabalho, resume-se apenas a alienação na própria atividade do trabalho [...] o trabalho é exterior ao trabalhador [...] não pertence a sua natureza; portanto ele não se afirma no trabalho, mas nega-se a si mesmo [...] não desenvolve livremente as energias físicas e mentais, mas esgota-se fisicamente e arruína o espírito. Por conseguinte, o trabalhador só se sente em si fora do trabalho, enquanto no trabalho se sente fora de si. Assim, o seu trabalho não é voluntario, mas imposto, é trabalho forçado (MARX, 1989, p.162). 
A alienação e o trabalho têm uma relação da subjetividade no da produção quando o trabalhador vende sua força de trabalho na atividade produtiva. Conforme (BRAGA; NETO,2012).

Marx critica os ideais dos principais pensadores da Economia Clássica:

Adam Smith (1723 - 1790) e David Ricardo (1772 - 1823) sobre a alienação do trabalhador para satisfazer a dominação da classe dominante. A doutrina econômica dos fisiocráticas representa o fortalecimento da produção econômica para alienar os trabalhadores.

Karl Marx aprofunda teoricamente o conceito de trabalho alienado nos manuscritos econômico-filosófico (1844) e faz uma crítica a economia política clássica moderna capitalista no pensamento de dois grandes pensadores da economia moderna: Adam Smith e David Ricardo. Estes fundamentaram teoricamente nos estudos filosóficos econômicos de que o trabalho humano é a verdadeira fonte de riqueza. Assim, Adam Smith e David Ricardo valorizam o trabalho na produção do ato produtivo do homem.

Adam Smith e David Ricardo desenvolvem os estudos no pensamento em que o comércio e a propriedade privada podem ser organizados na valorização dos indivíduos no ato produtivo. Então, o trabalho na produção vai ser a grande fonte de riqueza dos indivíduos.

O pensador marxista da atualidade, filósofo Húngaro Instiván Meszáros, na sua obra teoria que recebeu vários prêmios internacionais pela publicação: "Teoria da alienação", (1970), fundamenta em que no sistema de metabolismo social do capital da sociedade capitalista aliena os sujeitos na essência do ato produtivo. Mészáros discute que o trabalho alienado: "o trabalhador vai vender a força de trabalho como uma troca para alimentar" os modos de produção capitalista". Neste sentido, a mercadoria e o trabalhador se confundem na relação de troca e do ato produtivo para enriquecer os "donos da produção".

Desse modo, a sociedade moderna capitalista é o contexto histórico - social em que Marx fundamentou os estudos teóricos sobre trabalho e alienação. Na crítica a economia política da moderna, a teoria marxiana discorre nos manuscritos econômico- filosófico (1844) o conceito de trabalho alienado enquanto um processo de estranhamento do trabalhador e a fuga deste sujeito da humanização e das 
relações sociais para "fetichismo e mercadoria na soma do trabalho" do modo de produção capitalista. Assim, os estudos filosóficos de Marx das relações materialistas históricas pelos meios de produção capitalista teorizam a relação do trabalho e alienação. Por fim, o pensamento marxista discute a venda da força de trabalho para se transforma em um trabalho alienado na "confusão e estranhamento do homem" de trabalho e mercadoria nos meios de produção capitalista e como o trabalhador produz a riqueza e torna-se um sujeito pobre para aumentar o lucro para os capitalistas.

\section{CONSIDERAÇÕES FINAIS}

Nesse artigo foi apresentado uma discussão filosófica do conceito de trabalho na sociedade moderna capitalista. Assim, Marx faz uma reflexão teórica na economia política para fundamentar o trabalho e alienação no processo industrial.

Este estudo surgiu com a finalidade de trazer uma reflexão - ação com relevância social, científica na literatura teórica do conceito de trabalho alienado na sociedade moderna capitalista. Assim, Marx discute o conceito de trabalho alienado nos manuscritos econômicos - filosóficos e debate filosoficamente as críticas dos pensadores de Adam Smith e David Ricardo. Assim, as contribuições filosóficas são fundamentais para o fortalecimento cientifico.

Dessa forma, este estudo científico justifica-se pela necessidade de compreender os estudos marxistas no conceito de trabalho alienado dos sujeitos e dialogar filosoficamente pelo embate filosófico na sociedade moderna capitalista.

\section{REFERÊNCIAS}

ALVES, Luís Carlos Ribeiro. O homem e a alienação dos Manuscritos Econômicos-Filosóficos, v.1, n.2, p.164, 2012.

ANTUNES, Ricardo. Os sentidos do Trabalho. São Paulo: Boitempo.

ARRAIS NETO, Enéas. Crise do fordismo ou crise do capital: a relação essência fenômeno e as transformações do mundo do trabalho. 
ARRANHA, Maria Lúcia de Aruda. Introdução: Experiência Filosófica. São Paulo: Editora Moderna, 2012.

BRAGA, Océlio Jackson; NETO, Enéias Arrais. Trabalho alienado e a propriedade privada nos Manuscritos Econômicos-Filosóficos, v.1, n.4, p.60,2012.

BOTTOMOTE, Tom. Dicionário do pensamento marxista. 5a Ed. Rio de Janeiro: Zahar, 2012.

FROMM, Erich. Conceito marxista do homem. 5ㄹ Ed. Rio de Janeiro: Zahar Editores, 1970.

LUKÁCS, György. O trabalho. Tradução de Ivo Tonet. Disponível em: https://pt.scribd.com/document/161831993/Luckacs-Trabalho-a-Ontologia-Do-SerSocial social. Acesso em: 15/11/2017.

. Para uma ontologia do ser social. São Paulo: Editora Boitempo, 2012.

Para uma ontologia do ser social: os princípios ontológicos fundamentais de Marx. São Paulo: Ciências Humanas, 1979.

MARCUSE, Herbert. Razão e Revolução: Hegel e o advento da teoria social. 2.ed. Rio de Janeiro: Paz e Terra, 1978.

MARX, K. Manuscritos econômico-filosóficos: terceiro manuscrito. Trad. JoséCarlos Bruni. São Paulo: Ed. Abril, 1974. (Coleção Os Pensadores).

. Manuscritos econômico-filosóficos. In: MARX, Karl. Manuscritos econômico filosóficos e outros textos escolhidos. $5^{\mathrm{a}}$ Ed. São Paulo: Nova Cultural, Coleção os Pensadores, 1991.

El capital. 2.ed. México: Fondo de Cultura Económica, 1959. T.1.

. Manuscritos Econômico-Filosóficos. Lisboa: Edições 70, 1989.

Economistas, 1983.

O capital. Livro I, vol. 01. São Paulo: Editora Abril, Série Os

MÉSZÁROS, Istvan. A teoria da alienação em Marx. In: Mundo do trabalho. SCHNEIDE, Nélio. (Org). São Paulo: Boitempo,2016.

I. Marx: A Teoria da alienação. Rio de Janeiro: Zahar, 1981. 